\title{
Clinical and Echocardiographic Profile of Patients with Atrial Fibrillation Presenting in Tertiary Centre of Nepal
}

\author{
Kumud Bhattarai*, Ananta Bhakta Uprety \\ Department of Medicine, Bir Hospital, Kathmandu, Nepal
}

\begin{abstract}
BACKGROUND

This work is licensed under a Creative Commons Attribution 4.0 Unported License.

Atrial Fibrillation(AF) is one of the commonest arrhythmias with significant morbidity and mortality where there is uncoordinated activation of atrium leading to mechanical dysfunction of heart. Though rheumatic heart disease is very rare in the western world, it is still prevalent in developing country like Nepal. There is increased risk of development of heart failure, transient ischemic attack/stroke with increased rates of hospitalization.
\end{abstract}

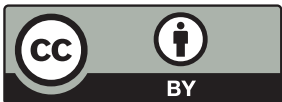

\section{METHODS}

This study was a descriptive cross sectional study done in 70 admitted cases of two tertiary centres of Kathmandu (Bir Hospital and Sahid Gangalal National Heart Centre) from February 2018 to August 2018, presenting with history and clinical examination suggestive of Atrial Fibrillation and diagnosis confirmed by 12 lead ECG.

\section{RESULTS}

Among 70 cases, female to male ratio was 2.2:1. The mean age of patients was $60.03 \pm 19.60$ years with dyspnea (91\%) followed by palpitation (76\%) being commonest presenting symptoms. $15 \%$ of cases presented with Stroke. The most common etiology was rheumatic Heart Disease (38.6\%) with female predominance. The most common valvular involvement was of mitral valve (71.4\%). 8.6\% of patients had clots in Left Atrium and majority had LA size $>4 \mathrm{~cm}$.

\section{CONCLUSION}

In contrary to the studies in the western world, the most common etiology of AF is rheumatic Heart Disease with patients of younger age group with female predominance. Majority of the cases had structural abnormalities in echocardiographic study and left atrial enlargement was common finding risking for thrombus formation and embolization.

\section{KEY WORDS}

Atrial fibrillation; Rheumatic Heart Disease; Echocardiography.

\section{BACKGROUND}

Atrial Fibrillation is the most common sustained arrhythmia withsignificantmorbidityandmortality. Itisasupraventricular arrhythmia characterized electrocardiographically by low amplitude base line oscillations ( fibrillatory $f$ waves) and an irregular ventricular rhythm. The electrical activity suggestive of $P$ waves may be seen in some leads. However distinct $p$ wave is absent.

In many cases, the patients may not complain of significant symptoms .However AF may presents as pounding heart(palpitations), chest pain, dyspnea, dizziness, lightheadedness or syncopal attacks. There is significant risks of developing stroke heart failure, hospitalization and death. ${ }^{1}$

The lifetime risks of developing AF is $25 \%$ in men and women 40 years of age and older.

The lifetime risks not considering congestive cardiac failure or myocardial infarction is around $16 \%$ for both men and women. ${ }^{2}$ Men are more likely than women to have atrial fibrillation regardless of age, and among older adults the prevalence is higher in white than in black populations. Various studies done in different parts of the world shows the advancing age being the major risk factor for developing $A F{ }^{3}$ There is a rise in incidence and prevalence of $A F$ resulting in increase in global burden of AF and thromboembolic complications resulting in stroke episodes. ${ }^{4}$

Chronic diseases associated with AF includes hypertensive

*Corresponding Author | Dr. Kumud Bhattarai, Department of Medicine, Bir Hospital, Kathmandu, Nepal | Email: kumudbhattarai3@gmail.com Phone: +977-9841502879. 
heart disease ${ }^{5}$, coronary artery disease ${ }^{6}$, rheumatic heart disease ${ }^{7}$, valvular heart disease ${ }^{8}$, heart failure ${ }^{9}$, congenital heart disease including atrial septal defect ${ }^{10}$, Ebstein anomaly, patent ductus arteriosus.

Subclinical markers indicating increased AF risk include increased arterial stiffness ${ }^{11}$ and echocardiography evidence of structural heart disease such as left atrial enlargement, left ventricular hypertrophy, and left ventricular systolic and diastolic dysfunction. ${ }^{12}$

\section{METHODOLOGY}

This study was a descriptive, cross-sectional study done in 70 patients admitted in two tertiary centres of kathmandu (Bir Hospital and Shahid Gangalal National Heart Centre). Patients presenting with history and clinical examination suggestive of AF and diagnosis confirmed by 12 lead ECG was included in the study. Every patients were evaluated with transthoracic echocardiography according to standard methods. Left atrial diameter was measured from $\mathrm{M}$ mode or 2 dimensional electrocardiography in parasternal long axis.All the statistical analysis were done from SPSS 20 software.

RESULTS

Table 1: Baseline characteristics of patients

\begin{tabular}{|l|l|}
\hline Age (years) $<20$ & $2(2.9 \%)$ \\
$20-39$ & $12(17.1)$ \\
$40-59$ & $18(25.7)$ \\
$>60$ & $38(54.3)$ \\
\hline Sex & \\
Female & $48(69 \%)$ \\
Male & $22(31 \%)$ \\
\hline Hypertension & $24.3 \%$ \\
\hline Alcohol consumption & $21.4 \%$ \\
\hline Diabetes & $8.6 \%$ \\
\hline Thyroid disorder & $5.7 \%$ \\
\hline
\end{tabular}

Table:2 Age Distribution in Patients with AF

\begin{tabular}{|l|l|l|}
\hline Age group(year) & Frequency $(\mathbf{n}=\mathbf{7 0})$ & Percentage \\
\hline$<20$ & 2 & 2.9 \\
\hline $20-39$ & 12 & 17.1 \\
\hline $40-59$ & 18 & 25.7 \\
\hline $60-79$ & 26 & 37.1 \\
\hline$>80$ & 12 & 17.1 \\
\hline Total & 70 & 100.0 \\
\hline
\end{tabular}

\section{Sex Distribution in Patients with AF}

Sex Distribution

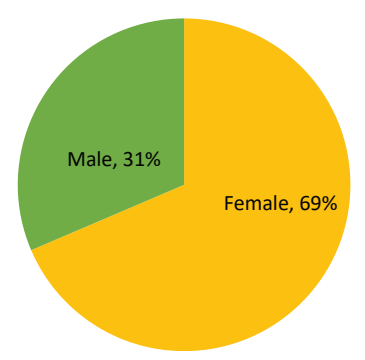

Fig 1: Sex Distribution in Patients with AF

Table:3 Presenting Complaints of AF

\begin{tabular}{|l|r|}
\hline Dyspnea & $91 . \%$ \\
\hline Palpitation & $76 \%$ \\
\hline Weekness/Fatigue & $68 \%$ \\
\hline Chest discomfort & $25 \%$ \\
\hline Stroke/TIA & $15 \%$ \\
\hline Syncope & $5 . \%$ \\
\hline
\end{tabular}

Most of the patients in our study had symptoms of Dyspnea (91\%) followed by palpitation (76\%). 64\% of patients presented with symptoms of heart failure ,25\% presented with chest pain, $18 \%$ of cases had features of Lightheadedness, 5\% cases presented with syncopal attack . Similarly $15 \%$ of cases presented with TIA/Stroke symptoms. None of the patients were asymptomatic

\section{Relationship of Atrial fibrillation with left Atrial Size}

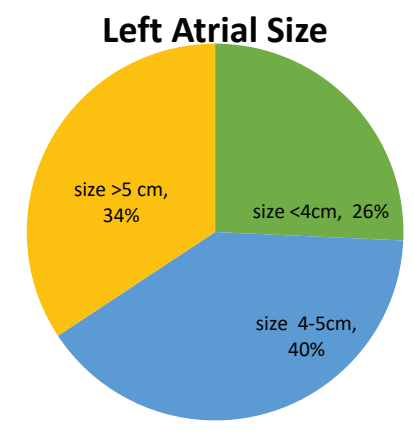

Fig 2: Pie Chart Showing Left Atrial Size in patients with AF

Mean LA size was $4.93 \pm 1.62 \mathrm{~cm}$. Size ranged from $2.3 \mathrm{~cm}$ $-11.5 \mathrm{~cm}$. Among them, $40 \%$ of cases had LA size of $4-5$ $\mathrm{cm}, 34 \%$ had size more than $5 \mathrm{~cm}$ and $26 \%$ had size less than $4 \mathrm{~cm}$. 
Table: 4 Etiology of Atrial Fibrillation

\begin{tabular}{|l|r|r|}
\hline Etiology & Frequency & Percenatge \\
\hline Rheumatic Heart Disease & 27 & 38.6 \\
\hline Coronary Artery Disease & 6 & 8.6 \\
\hline Hypertensive Heart Disease & 5 & 7.1 \\
\hline Cardiomyopathy & 9 & 12.9 \\
\hline COPD/ Corpulmonale & 11 & 15.7 \\
\hline Thyrotoxicosis & 3 & 4.3 \\
\hline $\begin{array}{l}\text { Valvular Heart Disease } \\
\text { (Degenerative) }\end{array}$ & 8 & 11.4 \\
\hline Mitral Valve prolapse & & \\
\hline Total & 70 & 1.4 \\
\hline
\end{tabular}

The most common etiology of AF in our study was Rheumatic Heart Disease (38.6\%). Among them $70.37 \%$ were female and $29.62 \%$ were male. Similarly the next common etiology in our study was COPD/ corpulmonale(15.7\%), cardiomyopathy (12.9\%), degenerative valvular heart disease (11.4\%), coronary artery disease (8.6\%), hypertensive heart disease (7.1\%), thyrotoxicosis (4.3\%) and mitral valve prolapse (1.4\%).

Table 5: Valvular Involvement in AF

\begin{tabular}{|l|r|r|}
\hline \multicolumn{3}{|c|}{ Valvular Involvement } \\
\hline & Frequency & Percent \\
\hline No valvular Lesion & 8 & 11.4 \\
\hline Mitral Stenosis(MS) & 11 & 15.7 \\
\hline Mitral Regurgitation(MR) & 28 & 40 \\
\hline Aortic Stenosis(AS) & 1 & 1.4 \\
\hline Aortic Regurgitation(AR) & 2 & 3 \\
\hline Tricispid & 9 & 13 \\
Regurgitation(TR) & 8 & 11.4 \\
\hline Mixed Lesion(MS,MR) & 3 & 4.2 \\
\hline Mixed lesion (mitral and & & 100.0 \\
Aortic) & 70 & \\
\hline Total & & \\
\hline
\end{tabular}

The most common valvular involvement in our study was of Mitral valve(71.4\%).Among them 15.6\% were isolated Mitral Stenosis (MS), 40\% were isolated MR. However $11.4 \%$ of cases has no valvular involvement which included cases of Thyrotoxicosis, Hypertension, CAD and COPD. Among RHD, $96 \%$ of the cases had Mitral valve involvement.

\section{DISCUSSION}

A total of 70 cases diagnosed as atrial fibrillation was studied from 2 different tertiary level hospitals in Kathmandu. Among them 69\% were Female and 31\% were Male. The ratio of Female to male was 2.2:1. This resembles the study performed by Gautam et al in Tertiary level Hospital of Nepal. ${ }^{13}$ Similar findings was seen in studies done by Singh R et $a^{14}$, Sastry $K$ et $a^{15}$. This findings differ from few studies where there is male predominance of Atrial Fibrillation. ${ }^{16-18}$

The mean age of patients presenting with AF was $60.03 \pm$ 19.60 years with median years of presentation being 62 years and age range from 18-90 years. Majority (54.2\%) of patients were above 60 years. The results of our study was in accordance to Singh $\mathrm{R}$ et al ${ }^{14}$ and Dhungana SP et al ${ }^{19}$ where majority of patients were older. The population prevalence of AF ranges from 2.3-3.4\% and incidence being on a rising trend. ${ }^{20}$ The incidence rate in overall is 9.9/1000 person -year with 1.1/1000 person-year in age group 5559 years and rising to $20.7 / 1000$ person year in a age group 85 years and above. ${ }^{21}$

Most of the patients in our study had symptoms of dyspnea (91\%) followed by palpitation (76\%). 64\% of patients presented with symptoms of heart failure, $25 \%$ presented with chest pain, $18 \%$ of cases had features of Lightheadedness, 5\% cases presented with syncopal attack . Similarly $15 \%$ of cases presented with TIA/Stroke symptoms. None of the patients were asymptomatic.

Hemodynamic consequences of AF may be due to variable combination of suboptimal ventricular rate control or loss of coordinated atrial contraction, beat to beat variability in ventricular filling and activation of autonomic nervous system. ${ }^{22,23}$

Presentation of patients therefore ranges from no symptoms to fatigue, palpitations, dyspnea, hypotension, syncope, or heart failure. ${ }^{24}$ Many times AF is associated with exacerbation of underlying heart disease, either because $\mathrm{AF}$ is a cause or consequence of deterioration or because it contributes directly to deterioration. ${ }^{25,26}$ Hypertensive heart disease and coronary heart disease are the commonest chronic disorders associated with atrial fibrillation in the developed countries. ${ }^{27}$ It is estimated that hypertension is responsible for $14 \%$ of all cases of $A F^{28}$

In our study , $24.3 \%$ of patients were hypertensive, $21.4 \%$ had history of alcohol consumption , 8.6\% were Diabetic, $5.7 \%$ patients had thyrotoxicosis. Different studies have shown atrial fibrillation being associated with chronic disease condition like Diabetes Mellitus ${ }^{\top}$. Similarly other triggers include acute alcohol consumption/alcohol abuse. Binge alcohol drinkers with or without alcoholic cardiomyopathy are at increased risk of developing AF mostly triggered during weekend, where there is increased alcohol intake, a phenomenon known as holiday heart syndrome. ${ }^{29}$

The most common etiology of AF in our study was theumatic heart disease (38.6\%). Among them 70.3\% were female and $29.7 \%$ were male. As RHD is common in areas with low socioeconomic backgrounds, overcrowding 
and high prevalence of throat infection with Group A beta hemolytic streptococci, it is more endemic in Asia, Africa and South America. ${ }^{30}$ The result of our study is consistent with the prevalence study done by Adhikari $\mathrm{K}$ et al in tertiary hospital of Kathmandu where $37.14 \%$ of the patients who had AF was diagnosed with RHD.

Majority of patients in our study had left atrial size more than $4 \mathrm{~cm}$. Among them, $40 \%$ of cases had LA size of $4-5 \mathrm{~cm}, 34 \%$ had size more than $5 \mathrm{~cm}$ and only $26 \%$ had size less than $4 \mathrm{~cm}$. Atrial size is further increased if AF is sustained. ${ }^{31}$ LA dilatation is associated with adverse remodeling of its wall, but debate arises whether AF is the initial cause or in fact the end result. ${ }^{32}$ Left atrial dimention more than $6 \mathrm{~cm}$ has greater chance of recurrence of $A F^{33}$ $8.6 \%$ of patients in our study had clots in Left Atrium.

AF increase the risk of stroke five times. ${ }^{34}$ Around $20 \%$ of all cases of stroke are related to thromboembolism secondary to Atrial Fibrillation. ${ }^{35}$ It is very important to decide about the use of oral anticoagulation or aspirin in case of AF for prevention of embolic episodes based on CHADS VAS score where score of $>1$ favours oral anticoagulant use to prevent embolization in non valvular $\mathrm{AF}^{36}$

The most common valvular involvement in our study was of Mitral valve (71.4\%). Among them $15.6 \%$ were isolated Mitral Stenosis (MS), 40\% were isolated mitral regurgitation (MR). However $11.4 \%$ of cases has no valvular involvement which included cases of thyrotoxicosis, hypertension, cjoronary artery disease and COPD. Among RHD,96\% of the cases had Mitral valve involvement.

Although any valvular lesion can predispose to AF, stenotic left sided lesion, particularly rheumatic heart disease has highest prevalence. ${ }^{7}$

\section{LIMITATION}

Since this is a hospital based study, it may not represent the real picture prevalent in the community setting. Though Sample size is small,it may be a base for further studies regarding $A F$.

\section{CONCLUSION}

Atrial Fibrillation is one of the commonest sustained arrhythmias with significant morbidity and mortality. This study has given basic clinical and echocardiographic profile of patients with AF.In contrary to the studies in the western world, the most common etiology of AF is Rheumatic Heart Disease with patients of younger age group with female predominance. Left atrial enlargement is frequently observed risk for thrombus formation and systemic embolisation.

\section{REFERENCES}

1. Benjamin EJ, Levy D, Vaziri SM, Belanger AJ WP. Independent risk factors for atrial fibrillation in a population-based cohort. The Framingham Heart Study. JAMA. 1994;271(11):840.

2. Lloyd-Jones DM, Wang TJ, Leip EP, Larson MG, Levy D, Vasan $\mathrm{RS}$, et al. Lifetime risk for development of atrial fibrillation: The framingham heart study. Circulation. 2004;110(9):1042-6.

3. P W. Paul Wood's Diseases of the Heart and circulation. 3rd ed. Lippincott; 1968. 278 p.

4. Lip GYH, Brechin CM, Lane DA. The Global Burden of Atrial Fibrillation and Stroke. Chest [Internet]. 2012 Dec];142(6):1489-98. Available from: http://www.ncbi.nlm.nih. gov/pubmed/22459778

5. Krahn AD, Manfreda J, Tate RB, Mathewson FA C TE. The natural history of AF:Incidence,risk factors and prognosis in the Manitoba Follow-Up Study. Am J Med. 1995;98(5):476-80.

6. Wong CK, White HD, Wilcox RG, Criger DA, Califf RM TE et al. New Atrial fibrillation after acute $\mathrm{MI}$ independently predicts death:The GUSTO-III experience. Am Hear J. 2000;140(6):878.

7. Diker E, Aydogdu S PK. Prevelence and Predictors of AF in Rheumatic Valvular heart disease. .Diker E,Aydogdu S,Polat k. 1996;77(1):96.

8. Grigioni F, Avierinos JF LL. AF complicating the course of degenerative Mitral Regurgitation:Determinants and long-term outcome. J Am Coll Cardiol. 2002;40(1):84.

9. Wang N, Larson MG, Vasan RS, Lee DS WT etal. AF Begets Heart failure and vice versa:Temporal associations and differences in preserved versus Reduced Ejection Fraction. Circulation. 2016;133(5):484-9.

10. Berger F, Vogel M, Kramer A LP. Incidence of Atrial flutter/ fibrillation in adults with atrial septal defect before and after surgery. Ann Thorasic Surg. 1999;68(1):75-9.

11. Mitchell GF, Vasan RS, Keyes MJ, Parise H et al. Pulse pressure and risk of new onset atrial fibrillation. JAMA. 2007;297:70915.

12. Nieuwlaat R, Capucci A, Camm AJ, Olsson SB, Andresen D, Davies DW, et al. Atrial fibrillation management: A prospective survey in ESC Member Countries - The Euro Heart Survey on atrial fibrillation. Eur Heart J. 2005;26(22):2422-34.

13. Gautam MP, Gautam S, Prasad SG, Subramanyam G, Ghimire $U$. A study of the clinical profile of atrial fibrillation in a tertiary care super-specialty referral centre in Central Nepal. J Coll Med Sci. 2012;8(3):9-16.

14. Singh R, Kashyap R, Bhardwaj R, Marwaha R, Thakur M, Singh TP, et al. The clinical and etiological profile of atrial fibrillation after echocardiography in a tertiary care centre from North India - a cross sectional observational study. Int J Res Med Sci. 2017;5(3):847-50.

15. Sastry KBR, Kumar LS, Anuradha P, Raj B, Afzal MAM. Clinical profile and Echocardiographic findings in patients with Atrial Fibrillation. 2016;6(2):44-7. 
16. Nanda V, Gupta AK MS et al. Etiological profile and clinical presentation of patients with atrial fibrillation from a rural area of Bihar. Natl J Med Res. 2012;2(2):124-7.

17. Furberg CD, Psaty BM MT et al. Prevalence of atrial fibrillation in elderly subject (the cardiovascular health study). Am J Cardiol. 1994;74(3):236-41.

18. Dhakal M. Epidemiology and Clinical Presentation of Patients With Atrial Fibrillation From a Tertiary Care Hospital of East Sikkim : an Observational Study. J Evol Med Dent Sci. 2013;2(20):3554-60.

19. Dhungana SP SK. Antithrombotic agents and Risk Profile of Patients with Atrial Fibrillation from Rural Part of Nepal. J Inst Med. 2015;16-21.

20. Ball J, Carrington MJ, McMurray JJV, Stewart S. Atrial fibrillation: Profile and burden of an evolving epidemic in the 21st century. Int J Cardiol [Internet]. 2013 Sep 1;167(5):1807-24. Available from: http://www.ncbi.nlm.nih.gov/pubmed/23380698

21. Heeringa J, Hofman A, Kors JA HV et al. Prevelence, Incidence and lifetime risk of atrial fibrillation :The Rotterdam Study. Eur Hear j. 2006;27(8):949-53.

22. Ikeda $T$, Murai $H$, Kaneko $S$ et al. Augmented single-unit muscle sympathetic nerve activity in heart failure with chronic atrial fibrillation. J Physiol. 2012;(590):509-18.

23. Segerson NM, Sharma N, Smith ML et al. The effects of rate and irregularity on sympathetic nerve activity in human subjects. Hear Rhythm. 2007;4:20-6.

24. Nabauer M, Gerth A, Limbourg $T$ et al. The Registry of the German Competence NETwork on Atrial Fibrillation: patient characteristics and initial management. Europace. 2009;11:423-34.

25. Jabre $P$, Jouven $X$, Adnet $F$ et al. Atrial fibrillation and death after myocardial infarction: a community study. Circulation. 2011;123:2094-100.

26. Olivotto I, Cecchi F, Casey SA et al. Impact of atrial fibrillation on the clinical course of hypertrophic cardiomyopathy. Circulation. $2001 ; 104: 2517-24$

27. Kannel WB, Abbott RD SD et al. Epidemiologic features of chronic atrial fibrillation: the Framingham study. N Engl J Med. 1982;306(17):1018.

28. Kannel WB, Wolf PA, Benjamin EJ LD. Prevalence, incidence, prognosis, and predisposing conditions for atrial fibrillation: population-based estimates. Am J Cardiol. 1998;82:2N-9N.

29. Ettinger PO, Wu CF, Cruz D L WA. Arrhythmias and the "Holiday Heart:"alcohol associated cardiac rhythm disorders. Am Hear J. 1978;95(5):555

30. MD Seckeler TH. The worldwide epidemiology of acute rheumatic fever and rheumatic heart disease. Clin Epidemiol. 2011;3:67.

31. Sanfilippo AJ, Abascal VM, Sheehan M, Hughes RA WA. Atrial enlargement as a consequence of atrial fibrillation. A prospective echocardiographic study. Circulation. 1990;82(3):792.
32. Casaclang-Verzosa G, Gersh BJ TT. Structural and functional remodeling of the left atrium: clinical and therapeutic implications for atrial fibrillation. J Am Coll Cardiol . 2008;51:111.

33. MA, Allen BJ, Capparelli EV, Luckett CR, Morton R HW. .Factors determining maintenance of Sinus rhythm after chronic atrial fibrillation with left atrial dilatation. Am J Cardiol. 1989;63(15):1065.

34. Healey JS, Connolly SJ GM et al. Subclinical atrial fibrillation and the risk of stroke. N Engl J Med. 2012;366(120-29).

35. Cotter PE, Martin PJ RL. Incidence of atrial fibrillation detected by implantable loop recorders in unexplained stroke. Neurology. 2013;80:1546-50.

36. Chao T-F, Liu C-J, Wang K-L, et al. Using the CHA2DS2-VASC Score for Refining Stroke Risk Stratification in 'Low-Risk' Asian Patients With Atrial Fibrillation. J Am Coll Cardiol [Internet]. 2014 Oct 21; 64(16):1658-65. Available from: http://www.ncbi. nlm.nih.gov/pubmed/25323252 